\title{
Climate Impacts of Carbonaceous and Other Non-Sulfate Aerosols: A Proposed Study
}

\author{
M.O. Andreae', W.R. Cofer, II $^{2}$ P.J. Crutzen 1 P.V. Hobbs ${ }^{3}$, J.M. Hollar RECEIVED \\ T. Kuhlbusch 5 , T. Novakov ${ }^{*}$, J.E. Penner ${ }^{*}$ \\ 1 Max Planck Institute for Chemistry, D-55020 Mainz, Germany \\ MAY 151996 \\ Q. STI \\ 2 Atmospheric Sciences Division, NASA Langley Research Center, Hampton, VA 23681 USA \\ 3 Atmospheric Sciences Department, University of Washington, Seattle, WA 98195 USA \\ ${ }^{4}$ Energy and Resources Group, University of California, Berkeley, CA 94720 USA \\ 5 Environmental Research Laboratory, US Environmental Protection Agency, Athens, GA 30605 USA \\ 6 Energy and Environment Division, Lawrence Berkeley Laboratory, One Cyclotron Road, Berkeley, CA \\ 94720 USA \\ 7 Global Climate Research Division, Lawrence Livermore National Laboratory, P.O. Box 808, Livermore, CA \\ 94551 USA \\ * To whom correspondence should be addressed
}

June 1995

This is an informal report intended primarily for internal or limited external distribution. The opinions and conclusions stated are those of the author and may or may not be those of the Laboratory.

Work performed under the auspices of the U.S. Department of Energy by the Lawrence Livermore National Laboratory under Contract W-7405-Eng-48. 


\section{DISCLAIMER}

This document was prepared as an account of work sponsored by an agency of the United States Government. Neither the United States Government nor the University of California nor any of their employees, makes any warranty, express or implied, or assumes any legal liability or responsibility for the accuracy, completeness, or usefulness of any information, apparatus, product, or process disclosed, or represents that its use would not infringe privately owned rights. Reference herein to any specific commercial products, process, or service by trade name, trademark, manufacturer, or otherwise, does not necessarily constitute or imply its endorsement, recommendation, or favoring by the United States Government or the University of California. The views and opinions of authors expressed herein do not necessarily state or reflect those of the United States Government or the University of California, and shall not be used for advertising or product endorsement purposes.

This report has been reproduced

directly from the best available copy.

Available to DOE and DOE contractors from the

Office of Scientific and Technical Information

P.O. Box 62, Oak Ridge, TN 37831

Prices available from (615) 576-8401, FTS 626-8401

Available to the public from the

National Technical Information Service

U.S. Department of Commerce

5285 Port Royal Rd.,

Springfield, VA 22161 


\section{DISCLAMIRR}

Portions of this doeument may be illegible in electronic inage products Images are produced from the best available original document. 


\title{
Climate Impacts of Carbonaceous and Other Non-Sulfate Aerosols: A Proposed Study
}

\begin{abstract}
In addition to sulfate aerosols, carbonaceous and other non-sulfate aerosols are potentially significant contributors to global climate change. We present evidence that strongly suggests that current assessments of the effects of aerosols on climate may be inadequate because major aerosol components, especially carbonaceous aerosols, are not included in these assessments. Although data on the properties and distributions of anthropogenic carbonaceous aerosols are insufficient to allow quantification of their climate impacts, the existing information suggests that climate forcing by this aerosol component may be significant and comparable to that by sulfate aerosols. We propose that a research program be undertaken to support a quantitative assessment of the role in climate forcing of non-sulfate, particularly carbonaceous, aerosols.
\end{abstract}

June 1995 


\title{
Contributors
}

\author{
M.O. Andreae \\ Max Planck Institute for Chemistry \\ D-55020 Mainz, Germany \\ W.R. Cofer, III \\ Atmospheric Sciences Disvision \\ NASA Langley Research Center \\ Hampton, VA 23681 \\ P.J. Crutzen \\ Max Planck Institute for Chemistry \\ D-55020 Mainz, Germany \\ P.V. Hobbs \\ Atmospheric Sciences Department \\ University of Washington \\ Seattle, WA 98195 \\ J.M. Hollander \\ Energy and Resources Group \\ University of California \\ Berkeley, CA 94720 \\ T. Kuhlbusch \\ National Research Council \\ clo Environmental Research Division \\ US Environmental Protection Agency \\ Athens, GA 30605 \\ T. Novakov* \\ Energy and Environment Division \\ Lawrence Berkeley Laboratory \\ One Cyclotron Road \\ Berkeley, CA 94720 \\ J.E. Penner* \\ Global Climate Research Division \\ Lawrence Livermore National Laboratory \\ P.O. Box 808 \\ Livermore, CA 94551
}

\footnotetext{
*To whom correspondence should be addressed.
} 


\section{INTRODUCTION}

Aerosol particles in the troposphere produced by anthropogenic activities have the potential to lower the globally averaged surface temperature of the earth (i.e., to offset greenhouse-gas warming to a greater or lesser extent). Aerosols may influence climate directly by backscattering and absorption of solar radiation, and indirectly by increasing cloud condensation nucleus (CCN) concentrations, which in turn increase cloud droplet concentrations and thus backscattering of solar radiation. Higher droplet concentrations may also increase the lifetimes of clouds and therefore the earth's cloud cover. Unlike greenhouse gases, anthropogenic aerosol particles are not uniformly distributed over the globe but are found with highest concentrations in regions influenced by fossil fuel and biomass burning. This nonuniform distribution, in conjunction with the greenhouse climate forcing, is expected to result in a differential spatial forcing with net heating in some areas and net cooling in others (Penner et al., 1994).

Atmospheric aerosol mass is composed of complex mixtures of natural and anthropogenic chemical species that include sulfates, other water-soluble inorganic compounds, carbonaceous material, seasalt, and mineral particles. Since the effects of aerosols on climate depend on the physical and chemical properties of the total aerosol, assessment of these effects should include all aerosol species. Of these species anthropogenic sulfate has been the subject of most modeling studies of both direct and indirect aerosol effects (Charlson et al.,1992; Taylor and Penner, 1994; Jones et al., 1994), although it is recognized that the other aerosol components may be important (IPCC, 1995). In fact, some modeling studies of forcing by non-sulfate aerosols are now available, but they are highly preliminary and mainly serve to illustrate the importance of the non-sulfate aerosols (Penner, 1994; Liousse et al., 1995; Haywood and Shine, 1995). One reason for the emphasis on sulfate aerosols in modeling studies is that only for the sulfate aerosols are both the optical and nucleation properties and the global distributions relatively well known.

In this document we focus principally on the carbonaceous aerosol component, which, next to sulfate, is possibly the most significant contributor to aerosol climate forcing because of its abundance and its optical and CCN properties (Penner, 1994; Andreae, 1995). For example, on a globally averaged basis, the estimated emissions of carbonaceous aerosols are close to $100 \mathrm{Tg} \mathrm{yr}^{-1}$ (Liousse et al., 1995), while those of 
anthropogenic sulfate aerosols are $120 \mathrm{Tg} \mathrm{yr}^{-1}$. Although we do not discuss inorganic non-sulfate aerosols (both water-soluble ammonium and nitrate particles and insoluble mineral particles, such as silica from coal combustion and dust particles from desert regions in Africa and Asia), we note that these have also not been adequately evaluated.

\section{CARBONACEOUS AEROSOLS}

\section{Composition}

Carbonaceous aerosols are composed of three classes of materials broadly referred to as black (also known as "elemental" or "graphitic"), organic, and carbonate carbon. (We note that the definitions of these materials are, at present, operational and method dependent.) Carbonaceous aerosols (as well as any other aerosols) may be further classified as primary and secondary, depending on their sources and formation mechanisms. Black carbon is the principal light-absorbing component of combustion aerosol. It is a primary pollutant produced by incomplete combustion of fossil and biomass fuels. Organic carbon is the most abundant carbonaceous species. It may be primary if introduced directly into the atmosphere in the form of particles by various combustion and natural sources, or secondary if produced in the atmosphere by gas-toparticle conversion of anthropogenic and biogenic precursor gases. The term "organic carbon" is used to denote the total organic aerosol fraction, which is composed of a large number of individual compounds that determine the optical and CCN properties of this fraction. Both organic and black carbon affect the extinction of solar radiation. Black carbon is the principal light-absorbing aerosol species (some dust particles and condensed aromatic hydrocarbons may also contribute to light absorption), while both organic and black carbon aerosols are light-scattering species. Carbonate carbon is a constituent of mineral dust. Because carbonate is found primarily as large particles, it will not be considered here.

\section{Sources}

To quantify the relative contributions of sulfate and carbonaceous (and other nonsulfate) aerosols in climate forcing, the concentrations of these aerosols and their relationships to sources have to be determined. 
The sources and origins of anthropogenic sulfate and carbonaceous aerosols are very different. Emissions of $\mathrm{SO}_{2}$ - the precursor of combustion-derived sulfate aerosol - depend on the amount of fuel burned, its sulfur content, and the presence or absence of emission controls. In contrast, combustion-derived, carbonaceous aerosols are only partly related to the amount of fuel burned and essentially unrelated to its sulfur content. Consequently, the relative mass concentrations of anthropogenic sulfate and carbonaceous aerosols over different regions are variable, depending on the kind, intensity, and distribution of their sources.

Regional differences in sulfate and organic aerosol mass concentrations are evident in the United States, where sulfate and organic mass concentrations have been measured at a number of remote locations (Malm et. al., 1994). An analysis of these data shows that organic aerosol concentrations are equal to or greater than sulfate in the western U.S., while sulfate dominates over organic aerosols in the eastern U.S. (Penner, 1994), comprising together about $75 \%$ of the fine aerosol mass. A cursory examination of regional $\mathrm{SO}_{2}$ and $\mathrm{CO}$ emissions illustrates the reasons for these regional differences. The $\mathrm{CO} / \mathrm{SO}_{2}$ emission ratios for the U.S. states west and east of the Mississippi River in 1985-87 were estimated to be 6.2 and 2.8 , respectively. This difference reflects the different fuels used in the western and eastern United States (Benkovitz, 1982). Since CO emissions are an indicator of incomplete combustion, it follows that the relative concentrations of combustion-derived sulfate and carbonaceous aerosols over these regions must be different. This illustrates that sulfate mass concentrations should not be taken as a surrogate for the total submicron aerosol mass even in regions where fossil fuel burning dominates.

In contrast to most continental regions in the northern hemisphere, where the aerosol is derived mostly from fossil fuel combustion, biogenic sulfur sources contribute to aerosols in marine atmospheres. In the tropical South American continental aerosols, carbonaceous material is the principal component derived predominantly from biomass burning and emissions from living vegetation (Talbot et al., 1988, 1990).

\section{Distribution}

A recent analysis shows that although ambient organic carbon concentrations have been measured at a number of marine and remote sites, parallel organic and sulfate measurements are extremely limited (Penner, 1994). Furthermore, with a few exceptions, the contributions of principal sources to the aerosol concentrations have not been 
established. For example, it is known that the aerosol in the tropics is dominated by carbonaceous matter from biomass burning (Andreae, 1991); but there is only fragmentary knowledge about the contributions of specific sources to organic and black carbonaceous aerosol concentrations over large parts of Eastern Europe, Latin America, and Asia, and particularly over the oceans.

Early studies by Hoffman and Duce $(1977,1974)$ showed similar submicron aerosol carbon mass concentrations in marine air of the northern and southern hemispheres. Similar conclusions were reached by Eichmann et al. $(1980,1979)$. Lack of significant hemispheric differences was at the time attributed to in-situ formation of organic aerosols. In contrast, the work of Cachier et al. (1986) and, more recently, Rau and Khalil (1993) indicate significantly higher total particulate carbon concentrations in the northern hemisphere. Carbon isotope studies suggest that the submicron organic aerosol is primarily of continental (combustion) origin (Cachier, 1989). Results from the Global Tropospheric Experiment (TRACE-A) aircraft measurement campaign over South America, the southern tropical Atlantic ocean, and southern Africa, indicate that biomass burning aerosols are transported at altitudes above the mixing layer over the oceans from continental Africa and to a lesser extent out from South America (Andreae et al., 1994). Therefore, it is possible that the particular combination of biomass sources existing at the time of measurement determines whether or not hemispheric concentration differences will be observed.

\section{CARBONACEOUS AEROSOLS AND CLIMATE FORCING}

The potential importance of anthropogenic and biogenic carbonaceous aerosols in climate forcing is suggested by the following evidence:

1. Optically absorbing aerosol material has been measured in remote continental and marine atmospheres. Chemical and spectroscopic evidence indicates that this species is primarily combustion-derived black carbon (Rosen et al., 1981; Rosen and Novakov, 1983, Andreae et al., 1984; Clarke, 1989).

2. Modeling (Penner et al., 1992) and observational (Kaufman and Holben, 1995) studies of biomass smoke particles have shown that these particles perturb the 
atmospheric radiation balance, and thus the climate, comparably to anthropogenic sulfate aerosols.

3. The mass concentrations of organic aerosol material are comparable to those of sulfate in the few rural and remote locations where parallel measurements of organic and sulfate components have been made (Heintzenberg, 1989; Penner, 1994).

4. Most of the sulfate and carbonaceous aerosol mass is found in the optically active range, where it can interact with solar radiation. Measurements have shown that carbonaceous aerosols are responsible for a large part of the light extinction in urban areas (Groblicki et al., 1981; Hasan and Dzubay, 1983; Shah et al., 1984), rural areas, (Trijonis, 1982), and remote continental areas (Malm et al., 1994). The extinction by carbonaceous aerosols is caused by both absorption which tends to heat, and scattering which tends to cool the atmosphere.

5. Several studies have shown that the concentrations of cloud condensation nuclei $(\mathrm{CCN})$ in the atmosphere cannot be explained by sulfate aerosols alone (Hegg et al., 1993; Novakov et al., 1994).

6. There is evidence that the organic aerosol component may contribute significantly to the ambient CCN number concentrations (Novakov and Penner, 1993; Rivera-Carpio et al., 1995).

7. Studies of biomass smoke have shown that these particles (which are mostly organic) are efficient cloud condensation nuclei (Warner and Twomey, 1967; Hobbs and Radke, 1969; Eagan et al., 1974; Hallett et al., 1989; Rogers et al. 1991). Large concentrations of soluble organic compounds detected in rain droplets in biomass burning regions suggest that smoke is also important in cloud formation (Andreae et al., 1990). (This soluble fraction may also alter the composition of cloud droplets and thus affect the in-cloud chemical reactions.)

Items 2 through 4 suggest that the sulfate and organic components probably contribute similarly to light scattering. Quantification of the contributions of organic aerosols to light scattering is at present limited because their deliquescent properties are not known. Biomass aerosols are believed to take up water at elevated humidities, which increases their scattering efficiency because the organic component is internally mixed with sulfate or other hygroscopic substances (see, for example, Penner et al., 1991). 
Items 5 through 7 suggest that $\mathrm{CCN}$ number concentrations cannot be calculated or estimated from sulfate mass concentrations alone since the contributions of nonsulfate, specifically organic, species may be significant. The relative contributions of sulfate and organic aerosols to the $\mathrm{CCN}$ number concentrations are determined by their mass fractions found in the size range below $<0.1 \mu \mathrm{m}$. (The size distributions of these components depend on the specific formation mechanisms.) We note, however, that because atmospheric aerosol particles in general consist of mixtures of organic and inorganic species, it has not been established whether the organic component is intrinsically $\mathrm{CCN}$ active (because of the hydrophilic nature of some organic compounds), or whether this component is intrinsically inactive and rendered $\mathrm{CCN}$ active only through association with water-soluble inorganic species.

\section{PROPOSED RESEARCH PROGRAM}

The above considerations suggest that current assessments of the effects of aerosols on climate may be inadequate because major non-sulfate aerosol components, especially organic material, are not included in these assessments. In the interest of stimulating discussion of this issue, we give below a partial list of the types of measurements and data interpretation that are needed to achieve a reasonable understanding of climate forcing by organic and other non-sulfate aerosols.

1. Representative long-term mass concentrations of carbonaceous, sulfate, and other aerosol species determined in parallel at a number of climatologically important locations. The data should be obtained for at least two size ranges: $\mathrm{D}_{\mathrm{p}}<1 \mu \mathrm{m}$ or $<0.5$ $\mu \mathrm{m}$ (light scattering range) and $\mathrm{D}_{\mathrm{p}}<0.1 \mu \mathrm{m}$ ( $\mathrm{CCN}$ range). At a minimum, surface concentrations are needed, but these should be periodically augmented by column concentrations.

2. Long-term measurements of wet deposition of all aerosol species at the same locations.

3. Mass size distribution of major aerosol species.

4. Aerosol number size distributions and $\mathrm{CCN}$ number concentrations. 
5. Extinction, scattering, and absorption coefficients of total and individual aerosol chemical components.

6. Measurements to aid in identifying the sources and production mechanisms of organic aerosols (carbon-13, carbon-14, and molecular markers). With these data, the carbonaceous aerosol material could be classified into categories such as fossil vs. contemporary and combustion vs. natural (biogenic) origin. Knowledge of the sources of organic aerosols is important; the calculated effects of increasing $\mathrm{CCN}$ from anthropogenic activity would be different if these were mainly natural or mainly anthropogenic.

7. Development of models that treat the size distribution of aerosols and are evaluated through comparison with the measurements cited above.

We envisage the implementation of this research to proceed by (a) ground-based measurements at selected sites, for example Global Atmospheric Watch (GAW) sites; (b) through large national and international research projects, for example, those initially proposed by the International Global Aerosol Program (IGAP 1994), which has been recently incorporated into Focus on Atmospheric Aerosols (FAA) of the International Global Atmopsheric Chemistry (IGAC) Project; and (c) integration and interpretation of experimental results through modeling activities.

The purpose of ground-based measurements is to obtain long-term data not readily obtainable from airborne measurement platforms. The long-term studies should include enough measurements of individual aerosol components that the total mass, determined independently, can be accounted for ("mass closure"). Ground-based studies can also address formation mechanisms, detailed chemical composition, and optical and physico-chemical properties of non-sulfate aerosols.

Chemical and physical measurements should be sufficiently detailed that the optical characteristics of aerosols can be predicted from theory and compared with optical and radiation measurements ("radiative closure"). This type of experiment and model interpretation can best be achieved through collaboration with existing larger projects, some of which are briefly mentioned below.

Several activities and tasks within the aerosol focus of IGAC are concerned with radiative closure issues but do not at this time explicitly emphasize measurements of carbonaceous aerosols. These include the task "Biological Component of the 
Atmospheric Aerosol (BICAA)" and the task "Radiative Properties of Aerosols (RADPRO)". Measurements on carbonaceous aerosols should be incorporated in some of the field projects planned in connection with the IGAC Aerosol Focus, e.g. the Tropospheric Aerosol Radiative Forcing Observational Experiment (TARFOX), and the Aerosol Characterization Experiment-2 (ACE-2). A modeling component relating to aerosols has been added to IGAC activity 6.6 "Global Integration and Modeling (GIM)". The component "Modeling the Effects of Aerosols on Radiative Forcing and Climate (MEARC)" also should take carbonaceous aerosols into account. Although the tasks "Sulfur and Carbonaceous Aerosols in the Arctic and their Radiative Forcing (SCAARF)" in IGAC activity 3.1 (Polar Atmospheric and Snow Chemistry) and "Biomass Burning Aerosols in the Tropics: Impact on Radiation Budget and Climate (BATIR)" In IGAC activity 2.3 (Biomass Burning Experiment, BIBEX) do emphasize carbonaceous aerosols, these projects could usefully be complemented by additional measurement and analytical capabilities to address some of the issues raised in this document.

NASA has initiated a subsonic-aircraft assessment program (SASS) aimed at determining the impacts of the current and future fleet of subsonic aircraft on the earth's radiation budget and climate. Aircraft exhaust is a complex mixture of black and organic carbon, nitrogen oxides, and sulfur oxides. Gaseous and particulate aircraft emissions have long atmospheric lifetimes because these are injected into the upper troposphere. Aerosols from these emissions may also influence the formation of climatologically important cirrus clouds. The SASS program could, therefore, be one of the starting points for the total aerosol characterization aimed at achieving both mass and radiative closure.

Acknowledgments. We thank R.J. Charlson for reviewing the manuscript and providing useful comments and suggestions. Portions of this work performed at Lawrence Berkeley Laboratory and Lawrence Livermore National Laboratory were supported by the U.S. Department of Energy, Office of Health and Environmental Research, Environmental Sciences Division under contract DE-AC03-76SF00098 at LBL, and contract W-7405-Eng-48 at LLNL. 


\section{References}

Andreae, M.O., T.W. Andreae, R.J. Ferek, and H. Raemdonck, Long-range transport of soot carbon in marine atmosphere, Sci. Total. Environ. 36, 73-80, 1984.

Andreae, M.O., R.W. Talbot, H. Berresheim, and K.M. Beecher, Precipitation chemistry in central Amazonia, J. Geophys. Res. 95, 16,987-16,999, 1990.

Andreae, M.O., Biomass burning: Its history, use, and distribution and its impact on environmental quality and global climate, in Global Biomass Burning: Atmospheric, Climatic, and Biospheric Implications, pp. 3- 21, ed. J.S. Levine, MIT Press, Cambridge, 1991.

Andreae, M. O., B. E. Anderson, D. R. Blake, J. D. Bradshaw, J. E. Collins, G. L. Gregory, G. W. Sachse, and M. C. Shipham, Influence of plumes from biomass burning on atmospheric chemistry over the equatorial Atlantic during CITE-3, $J$. Geophys. Res. 99, 12,793-12,808, 1994.

Andreae, M. O., Climatic effects of changing atmospheric aerosol levels, in World Survey of Climatology. Vol. 16: Future Climates of the World, edited by A. HendersonSellers, Elsevier, Amsterdam (in press, 1995).

Benkovitz, C.M., Compilation of an inventory of anthropogenic emissions in the United States and Canada, Atmos. Environ. 16, 1551-1563, 1982.

Cachier, H., P. Buat-Ménard, M. Fontugne, and R. Chesselet, Long-range transport of continentally-derived particulate carbon in marine atmosphere: Evidence from stable carbon isotope studies, Tellus 38B, 161-177, 1986.

Cachier, H., Isotopic characterization of carbonaceous aerosols, Aerosol Sci. Technol. 10, 379-385, 1989.

Charlson, R.J., S.E. Schwartz, J.M. Hales, R.D. Cess, J.A. Coakley, Jr., J.E. Hansen, and D.J. Hofmann, Climate forcing by anthropogenic aerosol, Science 255, 423-430, 1992.

Clarke, A.D., Aerosol light absorption by soot in remote environments, Aerosol Sci. \& Technol. 10, 161-171, 1989.

Eagan, R.C., P.V. Hobbs, and L.F. Radke, Measurements of cloud condensation nuclei and cloud droplet size distributions in the vicinity of forest fires, J. Appl. Meteorol. $13,553-557,1974$.

Eichmann, R., P. Neuling, G. Ketseridis, J. Hahn, R. Jaenicke, and C. Junge, N-alkane studies in the troposphere - I, Gas and particulate concentrations in North Atlantic air, Atmos. Environ. 13, 587-599, 1979.

Eichmann, R., G. Ketseridis, G. Schebeske, R. Jaenicke, J. Hahn, P. Warneck and C. Junge, $\mathrm{N}$-alkane studies in the troposphere - II: Gas and particulate concentrations in Indian Ocean air, Atmos. Environ. 14, 695-703, 1980.

Groblicki, P.J., G.T. Wolff, and R.J. Countess, Visibility-reducing species in the Denver "brown cloud" - I. Relationships between extinction and chemical composition, Atmos. Environ. 15, 2473-2484, 1981. 
Hallett, J., J.G. Hudson, and C.F. Rogers, Characterization of combustion aerosols for haze and cloud formation, Aerosol Sci. and Technol. 10, 70-83, 1989.

Hasan, H., and T.G. Dzubay, Apportioning light extinction coefficients to chemical species in atmospheric aerosols, Atmos. Environ. 17, 1573-1581, 1983.

Hegg, R.D., J. Ferek and P.V. Hobbs, Light scattering and cloud condensation nucleus activity of sulfate aerosol measured over the northeastern Atlantic Ocean, $J$. Geophys. Res. 98, 14887-14894, 1993.

Heintzenberg, J., Fine particles in the global troposphere: A review. Tellus 41B, 149-160, 1989.

Hobbs, P.V., and L.F. Radke, Cloud condensation nuclei from a simulated forest fire, Science 163, 279-280, 1969.

Hoffman, E.J., and R.A. Duce, The organic carbon content of marine aerosol collected on Bermuda, J. Geophys. Res. 79, 4474-4477, 1974.

Hoffman. E.J., and R.A. Duce, Organic carbon in marine particulate matter: Concentration and particle size distribution, Geophys. Res. Letters 4, 449-452, 1977.

IGAP, A plan for an international global aerosol program, ed. P.V. Hobbs, 1994.

IPCC, Climate Change 1994: Radiative Forcing of Climate, Intergovernmental Panel on Climate Change, Report to IPCC from the Scientific Assessment Working Group (WGI), Cambridge University Press, Cambridge, 1995.

Jones, A., D.L. Roberts, and A. Slingo, Indirect radiative forcing by anthropogenic sulphate aerosols, Nature 370, 450-453, 1994.

Kaufman, Y.J., and B. N. Holben, Hemispherical backscattering by biomass burning and sulfate particles derived from sky measurements, J. Geophys. Res. (in press, 1995).

Liousse, C., J.E. Penner, C. Chuang, J.J. Walton, H. Eddleman, and H. Cachier, Modeling carbonaceous aerosols, submitted to J. Geophys. Res., 1995:

Malm, W.C., J.F. Sisler, D. Huffman, R.A. Eldred, and T.A. Cahill, Spatial and seasonal trends in particle concentration and optical extinction in the United States, $J$. Geophys. Res. 99, 1347-1370, 1994.

Novakov, T., and J.E. Penner, Large contribution of organic aerosols to cloudcondensation-nuclei concentrations, Nature 365, 823-826, 1993.

Novakov, T., C. Rivera-Carpio, J.E. Penner, and C.F. Rogers, The effect of anthropogenic sulfate aerosols on marine cloud droplet concentrations, Tellus $46 \mathrm{~B}$, 132-141, 1994.

Penner, J.E., S.J. Ghan, and J.J. Walton, The role of biomass burning in the budget and cycle of carbonaceous soot aerosols and their climate impact, in Global Biomass Burning: Atmospheric, Climatic, and Biospheric Implications, pp. 387-393, ed. J.S. Levine, MIT Press, Cambridge, 1991. 
Penner, J.E., R. Dickinson, and C. O'Neill, Effects of aerosols from biomass burning on the global radiation budget, Science 256, 1432-1434, 1992.

Penner, J.E., R.J. Charlson, J.M. Hales, N. Laulainen, R. Leifer, T. Novakov, J. Ogren, L.F. Radke, S.E. Schwartz, and L. Travis, Quantifying and minimizing uncertainty of climate forcing by anthropogenic aerosols, Bull. Am. Meteorol. Soc. 75, 375-400, 1994.

Penner, J.E., Carbonaceous aerosols influencing atmospheric radiation: black and organic carbon, in Aerosol Forcing of Climate, ed. R.J. Charlson and J. Heintzenberg, Wiley and Sons, Chichester, 1995.

Rau, J.A., and M.A.K. Khalil, Anthropogenic contributions to the carbonaceous content of aerosols over the Pacific Ocean, Atmos. Environ. 27A, 1297-1307, 1993.

Rivera-Carpio, C.A., C.E. Corrigan, T. Novakov, J.E. Penner, C.F. Rogers, and J.C. Chow, Derivation of contributions of sulfate and carbonaceous aerosols to cloud condensation nuclei from mass size distributions, J. Geophys. Res. (in press, 1995).

Rogers, C.F., J.G. Hudson, B. Zielinska, R.L. Tanner, J. Hallett, and J.G. Watson, Cloud condensation nuclei from biomass burning, in Global Biomass Burning: Atmospheric, Climatic, and Biospheric Implications, pp. 432-438, Ed. J.S. Levine, MIT Press, Cambridge, 1991.

Rosen, H., T. Novakov, and B. Bodhaine, Soot in the Arctic, Atmos. Environ. 15, 1371 $1374,1981$.

Rosen, H., and T. Novakov, Combustion generated carbon particles in the Arctic atmosphere, Nature 306, 768-770, 1983.

Shah, J.J., J.G. Watson, Jr., J.A. Cooper, and J.J. Huntzicker, Aerosol chemical composition and light scattering in Portland, Oregon: The role of carbon, Atmos. Environ. 18, 235-240, 1984.

Talbot, R. W., M. O. Andreae, T. W. Andreae, and R. C. Harriss, Regional aerosol chemistry of the Amazon Basin during the dry season, J. Geophys. Res. 93, 1499$1508,1988$.

Talbot, R. W., M. O. Andreae, H. Berresheim, P. Artaxo, M. Garstang, R. C. Harriss, K. M. Beecher, and S. M. Li, Aerosol chemistry during the wet season in Central Amazonia: The influence of long-range transport, J. Geophys. Res. 95, 16,955$16,969,1990$.

Taylor, K. and J.E. Penner, Response of the climate system to atmospheric aerosols and greenhouse gases, Nature 369, 734-737, 1994.

Trijonis, J., Existing and natural background levels of visibility and fine particles in the rural east, Atmos. Environ. 16, 2431-2445, 1982.

Warner, J., and S. Twomey, The production of cloud nuclei by cane fires and the effect on cloud droplet concentration, J. Appl. Meteorol. 24, 704-706, 1967. 